\title{
Increased ethanol consumption following chronic psychosocial stress: do oxytocin and baclofen hold any therapeutic promise?
}

\author{
Mary R. Lee ${ }^{1,2}$, Jared W. Bollinger ${ }^{1}$ and Lorenzo Leggio ${ }^{1,2,3} *$ \\ 1 Section on Clinical Psychoneuroendocrinology and Neuropsychopharmacology, Laboratory of Clinical and Translational Studies, National Institute on Alcohol Abuse \\ and Alcoholism, National Institutes of Health, Bethesda, MD, USA \\ 2 Intramural Research Program, National Institute on Drug Abuse, National Institutes of Health, Baltimore, MD, USA \\ ${ }^{3}$ Department of Behavioral and Social Sciences, Center for Alcohol and Addiction Studies, Brown University, Providence, RI, USA \\ ${ }^{*}$ Correspondence: lorenzo.leggio@nih.gov \\ Edited by: \\ Lara Ray, University of California, Los Angeles, USA \\ Reviewed by: \\ Daniel Roche, University of California, Los Angeles, USA \\ Emma Childs, The University of Chicago, USA
}

Keywords: ethanol consumption, chronic psychosocial stress, stress model, chronic subordinate colony housing, anxiety, oxytocin, baclofen

Both chronic stress (1) and anxiety disorders (2) are risk factors for developing alcohol use disorders (AUDs). Conversely, chronic alcohol consumption can increase anxiety via a rebound effect and acute withdrawal symptoms, thus contributing to anxiety-related development of AUDs and their maintenance (3). As such, there is a rationale and growing interest in developing medications with antistress and/or anxiolytic properties as putative treatments for AUDs. To this end, animal models that approximate or are relevant to human conditions of chronic stress and anxiety are relevant to test the effect of potential medications on alcohol-seeking behaviors.

Many rodent models of stress use either conditioned responses (e.g., shocks paired with stimuli) or unconditioned responses (e. g., natural predators) to provoke anxiety (4). Yet these models are of limited relevance to the experience of chronic psychosocial stressors and the resultant anxiety disorders seen in humans. In the study discussed here, Peters and colleagues (5) used a mouse model of chronic psychosocial stress previously developed by the same group (6). The model involves chronic subordinate colony housing (CSC), where a mouse is placed in the same cage with a socially dominant mouse for 19 days. The corresponding control condition is where the mouse is in a single housing $(\mathrm{SH})$ for the same duration. Previous studies with this model, using male mice only, reveal that CSC effects increased anxiety behavior as measured by elevated plus maze and light-dark box $(6,7)$. Accompanying this anxiety behavior is a reduction body weight gain and thymus weight, increased adrenal weight, and blunted cortisol response to circadian stimulation in vivo and adrenocorticotropic hormone (ACTH) challenge in vitro. The dysregulation observed in biomarkers of stress response perhaps explains the colonic inflammatory response also observed in this model (6). However, in vivo, cortisol levels were elevated in CSC mice compared to $\mathrm{SH}$ mice during $5 \mathrm{~min}$ exposure to an elevated platform, indicating intact acute stress response (8). Interestingly, exposure to CSC differentially affects hypothalamic expression of vasopressin and oxytocin in the paraventricular nucleus with an increase in the former and no change in the latter (7).

In the present study (5), the authors first validated 14 (vs. the previously validated 19) days of CSC as a stress provocation. Fourteen days of CSC resulted in increased anxiety behavior, as measured by significantly less time spent in the lit box compared to SH mice. Second, they demonstrated that this stressor led to increased ethanol consumption and preference without affecting the same for sweet or aversive non-alcoholic substances, thus suggesting an effect that is specific for alcohol-related behaviors.

The authors also tested the effect of two anxiolytic molecules, baclofen, and oxytocin, on drinking behavior as a consequence of CSC compared to SH. Both baclofen and oxytocin have been proposed as medications for AUDs. Intriguingly, there is preliminary evidence that the anxiolytic, anti-craving action of baclofen might be mediated, perhaps, by an oxytocinergic mechanism in the supraoptic nucleus of the hypothalamus (9). However, in this study the combination of baclofen and oxytocin was not investigated, nor the effects of baclofen on oxytocin levels. Therefore, future studies are warranted to address whether they share common pathways of action.

In preclinical studies, baclofen decreases chronic ethanol consumption in rodents undergoing the alcohol-water "free choice" paradigm $(10,11)$. Baclofen also reduces lever presses for alcohol in mice and rats (12-16). Perhaps most relevant to study discussed here is that post-dependent rats in a state of withdrawal (which is anxiogenic) after given baclofen, show decreased alcohol self-administration, anxiety behaviors, tremors, and seizures (10, 17-19).

A few human studies show additional promise of baclofen in reducing ethanol consumption and anxiety symptoms. Two double-blind placebocontrol studies demonstrated that baclofen is superior to placebo in preventing relapse $(20,21)$ [but see (22) for conflicting results]. Decreased anxiety levels and biomarkers of the stress response in alcoholic participants are also seen after administration of baclofen (20, 
23-25). Furthermore, consistent with the preclinical literature, clinical studies show that baclofen may be effective in reducing alcohol withdrawal symptoms, including withdrawal-related anxiety levels $(26,27)$.

As for oxytocin, much of the animal research investigating oxytocin within the context of addiction have centered on its ability to inhibit and reverse tolerance to ethanol and morphine (28). Additionally, oxytocin has been shown to decrease alcohol preference (29). In alcohol preferring rats, a single administration oxytocin, i.p. ( $1 \mathrm{mg} / \mathrm{kg}$ ) prior to alcohol access, resulted in significantly reduced preference for alcohol lasting 6 weeks (29). To our knowledge, only one small pilot clinical trial in heavy drinkers, has examined the effects of oxytocin on alcohol withdrawal symptoms. Compared with placebo, oxytocin significantly decreased withdrawal symptoms and reduced the amount of lorazepam administered "as needed" during detoxification (30).

In the study by Peters and colleagues, after establishing that 14 days of CSC results in significantly increased anxiety behavior and increased alcohol consumption and preference, this rodent model of stress and anxiety was used to test the effect of baclofen and oxytocin on subsequent drinking behavior. A single dose each of systemic baclofen, oxytocin, and vehicle as well as a single dose of intracerebroventricular (i.c.v.) oxytocin or vehicle was given following 2 weeks of a two bottle free choice period of increasing concentrations of ethanol up to $8 \%$. Ethanol consumption and preference were the main outcome measures, with saccharine and quinine as positive and negative controls, respectively. Baclofen significantly reduced alcohol consumption and preference in both groups of mice. In contrast, oxytocin reduced alcohol consumption only with peripheral administration and only in the SH group. For both drugs, there was a compensatory increase in water consumption, with no significant difference from baseline in total liquid consumption.

A fundamental question, evaluating the results of this study, is the effect of increased alcohol consumption on the anxiogenic phenotype in the CSC group. While the CSC mice exhibit more anxiety behavior and consume more alcohol, the experimental design did not allow for determination of anxiety-like behavior as a consequence of both CSC and alcohol consumption. Therefore, one cannot say whether the stress manipulation together with the exposure to alcohol also resulted in an anxiogenic phenotype. This is important in evaluating the observed effect of both drugs on drinking behavior in the context of each drug's anxiolytic properties.

It is interesting that baclofen and oxytocin have been shown to decrease alcohol consumption and/or decrease anxietyrelated alcohol withdrawal symptoms, both in rodents $(10,28,29)$ and in humans $(26,27,30,31)$. However, in this CSC model of anxiety, resulting in induced elevation of alcohol consumption, neither drug was specific for reducing alcohol consumption in the context of stress-induced anxiety.

In preclinical studies using similar paradigms for testing anxiety such as the elevated plus maze, baclofen, when given in doses comparable to those used in this study $(3.0 \mathrm{mg} / \mathrm{kg})$, is not anxiolytic. Rather, administration of baclofen results in a nonspecific behavioral inhibition (32). Further, in the specific test used in this study to measure anxiety, the light-dark box, while baclofen has not been studied, a GABA $_{B}$ receptor antagonist shows no anxiogenic effect (33). With respect to alcohol, in contrast, in rodent studies, baclofen (1.25 and $2.5 \mathrm{mg} / \mathrm{kg}$ ) reduces measures of anxiety from alcohol $(18,34)$. In humans, it decreases the anxiety associated with alcohol withdrawal, as stated above. Considering, therefore, the results of the study by Peters and colleagues, it is possible that the effect of baclofen was to produce a decrease in the rewarding property of alcohol in both housing contexts, that is, the drug's effect was not specific for the anxiogenic phenotype driving increased alcohol consumption.

The results for oxytocin mirror those seen in another rodent study examining the effect of oxytocin on alcohol consumption outside of a stress context (29). In this study by McGregor and colleagues (29) a single dose of oxytocin (a tenth of that used in the present study: $1 \mathrm{mg} / \mathrm{kg}$ ) given i.p. reduced alcohol consumption over 6 weeks, without a significant overall change in fluid intake. Notably, Peters and colleagues administered oxytocin both peripherally and centrally, but no effects were seen when it was administered centrally. It is difficult, however, to speculate why central administration did not replicate the same findings of when oxytocin was given i.p. Furthermore, it is unclear why given oxytocin's well demonstrated anxiolytic effect (35) there was no effect of oxytocin on alcohol consumption post stress-induced anxiety? Despite the anxiogenic phenotype produced as a consequence of CSC, the CSC model has not been shown to impact oxytocin expression, at least in the paraventricular nucleus of the hypothalamus (36). There might, though, be other brain regions where oxytocin is upregulated, such as the suproptic nucleus where dendritic release has been shown to impact CNS oxytocin levels (37). Further, in other stress models, such as social defeat, there is an upregulation of oxytocin receptor mRNA in the lateral septum and medial amygdala (38). If endogenous oxytocin was modulated due to the CSC stressor, then perhaps no effect of a single dose of intraperitoneal or intracerebroventricular oxytocin was apparent due to a ceiling effect of oxytocin resulting from the stressor. Further research into the neural pathways modulated by both oxytocin and baclofen with respect to drinking behavior in this stress model is warranted. In summary, further characterization of this rodent social stress model to investigate anxiety-like behavior after both stress and alcohol exposure would inform the use of this model to test medications that are themselves anxiolytic. Also, alternative experimental designs employing this animal model might include either administration of the medication of interest before the stress manipulation to see if the medication protects against development of anxiety and/or increased alcohol consumption, or after the social stressor but before alcohol exposure.

\section{ACKNOWLEDGMENTS}

This work was supported by the Division of Intramural Clinical and Biological Research of the National Institute on Alcohol Abuse and Alcoholism (NIAAA) and the Intramural Research Program of the National Institute on Drug Abuse (NIDA). The content is solely the responsibility 
of the authors and does not necessarily represent the official views of the National Institutes of Health.

\section{REFERENCES}

1. Sinha R. How does stress increase risk of drug abuse and relapse? Psychopharmacology (Berl) (2001) 158(4):343-59. doi:10.1007/s002130100917

2. Kushner MG, Abrams K, Borchardt C. The relationship between anxiety disorders and alcohol use disorders: a review of major perspectives and findings. Clin Psychol Rev (2000) 20(2):149-71. doi:10.1016/S0272-7358(99)00027-6

3. Koob GF. Theoretical frameworks and mechanistic aspects of alcohol addiction: alcohol addiction as a reward deficit disorder. Curr Top Behav Neurosci (2013) 13:3-30. doi:10.1007/7854_2011_129

4. Bourin M, Petit-Demouliere B, Dhonnchadha BN Hascoet M. Animal models of anxiety in mice. Fundam Clin Pharmacol (2007) 21(6):567-74. doi:10. 1111/j.1472-8206.2007.00526.x

5. Peters S, Slattery DA, Flor PJ, Neumann ID, Reber SO. Differential effects of baclofen and oxytocin on the increased ethanol consumption following chronic psychosocial stress in mice. Addict Biol (2013) 18(1):66-77. doi:10.1111/adb.12001

6. Reber SO, Birkeneder L, Veenema AH, Obermeier F, Falk W, Straub RH, et al. Adrenal insufficiency and colonic inflammation after a novel chronic psycho-social stress paradigm in mice: implications and mechanisms. Endocrinology (2007) 148(2):670-82. doi:10.1210/en.2006-0983

7. Reber SO, Neumann ID. Defensive behavioral strategies and enhanced state anxiety during chronic subordinate colony housing are accompanied by reduced hypothalamic vasopressin, but not oxytocin, expression. Ann N Y Acad Sci (2008) 1148:184-95. doi:10.1196/annals.1410.003

8. Uschold-Schmidt N, Nyuyki KD, Fuchsl AM, Neumann ID, Reber SO. Chronic psychosocial stress results in sensitization of the HPA axis to acute heterotypic stressors despite a reduction of adrenal in vitro ACTH responsiveness. Psychoneuroendocrinology (2012) 37(10):1676-87. doi:10.1016/j. psyneuen.2012.02.015

9. Marques de SL, Franci CR. GABAergic mediation of stress-induced secretion of corticosterone and oxytocin, but not prolactin, by the hypothalamic paraventricular nucleus. Life Sci (2008) 83(1920):686-92. doi:10.1016/j.lfs.2008.09.007

10. Colombo G, Agabio R, Carai MA, Lobina C, Pani M, Reali R, et al. Ability of baclofen in reducing alcohol intake and withdrawal severity: I - preclinical evidence. Alcohol Clin Exp Res (2000) 24(1):58-66. doi:10.1111/j.1530-0277. 2000.tb04554.x

11. Daoust M, Saligaut C, Lhuintre JP, Moore N, Flipo JL, Boismare F. GABA transmission, but not benzodiazepine receptor stimulation, modulates ethanol intake by rats. Alcohol (1987) 4(6):469-72. doi:10.1016/0741-8329(87)90087-5

12. Anstrom KK, Cromwell HC, Markowski T, Woodward DJ. Effect of baclofen on alcohol and sucrose self-administration in rats. Alcohol Clin Exp Res (2003) 27(6):900-8. doi:10.1111/j.15300277.2003.tb04414.x
13. Besheer J, Lepoutre V, Hodge CW. GABA(B) receptor agonists reduce operant ethanol selfadministration and enhance ethanol sedation in C57BL/6J mice. Psychopharmacology (Berl) (2004) 174(3):358-66. doi:10.1007/s00213-0031769-3

14. Janak PH, Michael GT. Comparison of the effects of allopregnanolone with direct GABAergic agonists on ethanol self-administration with and without concurrently available sucrose. Alcohol (2003) 30(1):1-7. doi:10.1016/S0741-8329(03)00068-5

15. Maccioni P, Serra S, Vacca G, Orru A, Pes D Agabio R, et al. Baclofen-induced reduction of alcohol reinforcement in alcohol-preferring rats. Alcohol (2005) 36(3):161-8. doi:10.1016/j.alcohol. 2005.08.003

16. Walker BM, Koob GF. The gamma-aminobutyric acid-B receptor agonist baclofen attenuates responding for ethanol in ethanol-dependent rats. Alcohol Clin Exp Res (2007) 31(1):11-8. doi:10. 1111/j.1530-0277.2006.00259.x

17. Colombo G, Serra S, Vacca G, Carai MA, Gessa GL. Baclofen-induced suppression of alcohol deprivation effect in Sardinian alcohol-preferring $(\mathrm{sP})$ rats exposed to different alcohol concentrations. Eur Pharmacol (2006) 550(1-3):123-6. doi:10.1016/j. ejphar.2006.08.052

18. File SE, Zharkovsky A, Gulati K. Effects of baclofen and nitrendipine on ethanol withdrawal responses in the rat. Neuropharmacology (1991) 30(2):183-90. doi:10.1016/0028-3908(91) 90202-M

19. Knapp DJ, Overstreet DH, Breese GR. Baclofen blocks expression and sensitization of anxietylike behavior in an animal model of repeated stress and ethanol withdrawal. Alcohol Clin Exp Res (2007) 31(4):582-95. doi:10.1111/j.15300277.2007.00342.x

20. Addolorato G, Caputo F, Capristo E, Domenicali M, Bernardi M, Janiri L, et al. Baclofen efficacy in reducing alcohol craving and intake: a preliminary double-blind randomized controlled study. Alcoho Alcohol (2002) 37(5):504-8. doi:10.1093/alcalc/37. 5.504

21. Addolorato G, Leggio L, Ferrulli A, Cardone S Vonghia L, Mirijello A, et al. Effectiveness and safety of baclofen for maintenance of alcohol abstinence in alcohol-dependent patients with liver cirrhosis: randomised, double-blind controlled study. Lancet (2007) 370(9603):1915-22. doi:10.1016/ S0140-6736(07)61814-5

22. Garbutt JC, Kampov-Polevoy AB, Gallop R, KalkaJuhl L, Flannery BA. Efficacy and safety of baclofen for alcohol dependence: a randomized, doubleblind, placebo-controlled trial. Alcohol Clin Exp Res (2010) 34(11):1849-57. doi:10.1111/j.1530-0277. 2010.01273.x

23. Flannery BA, Garbutt JC, Cody MW, Renn W Grace K, Osborne M, et al. Baclofen for alcohol dependence: a preliminary open-label study. Alcohol Clin Exp Res (2004) 28(10):1517-23. doi:10. 1097/01.ALC.0000141640.48924.14

24. Leggio L, Ferrulli A, Cardone S, Malandrino N, Mirijello A, D'Angelo C, et al. Relationship between the hypothalamic-pituitary-thyroid axis and alcohol craving in alcohol-dependent patients: a longitudinal study. Alcohol Clin Exp Res (2008) 32(12):2047-53. doi:10.1111/j.1530-0277. 2008.00792.x
25. Leggio L, Ferrulli A, Cardone S, Miceli A, Kenna GA, Gasbarrini G, et al. Renin and aldosterone but not the natriuretic peptide correlate with obsessive craving in medium-term abstinent alcoholdependent patients: a longitudinal study. Alcohol (2008) 42(5):375-81. doi:10.1016/j.alcohol.2008. 03.128

26. Addolorato G, Leggio L, Abenavoli L, Agabio $\mathrm{R}$, Caputo F, Capristo E, et al. Baclofen in the treatment of alcohol withdrawal syndrome: a comparative study vs. diazepam. Am J Med (2006) 119(3):276-8. doi:10.1016/j.amjmed.2005. 08.042

27. Lyon JE, Khan RA, Gessert CE, Larson PM, Renier CM. Treating alcohol withdrawal with oral baclofen: a randomized, double-blind, placebocontrolled trial. J Hosp Med (2011) 6(8):469-74. doi:10.1002/jhm.928

28. Kovacs GL, Sarnyai Z, Szabo G. Oxytocin and addiction: a review. Psychoneuroendocrinology (1998) 23(8):945-62. doi:10.1016/S0306-4530(98) 00064-X

29. McGregor IS, Bowen MT. Breaking the loop: oxytocin as a potential treatment for drug addiction. Horm Behav (2012) 61(3):331-9. doi:10.1016/j. yhbeh.2011.12.001

30. Pedersen CA, Smedley KL, Leserman J, Jarskog LF, Rau SW, Kampov-Polevoi A, et al. Intranasal oxytocin blocks alcohol withdrawal in human subjects. Alcohol Clin Exp Res (2013) 37(3):484-9. doi:10.1111/j.1530-0277.2012.01958.x

31. Addolorato G, Caputo F, Capristo E, Janiri L, Bernardi M, Agabio R, et al. Rapid suppression of alcohol withdrawal syndrome by baclofen. Am $J$ Med (2002) 112(3):226-9. doi:10.1016/S00029343(01)01088-9

32. Dalvi A, Rodgers RJ. GABAergic influences on plus-maze behaviour in mice. Psychopharmacology (Berl) (1996) 128(4):380-97. doi:10.1007/ s002130050148

33. Mombereau C, Kaupmann K, Froestl W, Sansig G van der Putten $\mathrm{H}$, Cryan JF. Genetic and pharmacological evidence of a role for $\mathrm{GABA}(\mathrm{B})$ receptors in the modulation of anxiety- and antidepressantlike behavior. Neuropsychopharmacology (2004) 29(6):1050-62. doi:10.1038/sj.npp.1300413

34. File SE, Zharkovsky A, Hitchcott PK. Effects of nitrendipine, chlordiazepoxide, flumazenil and baclofen on the increased anxiety resulting from alcohol withdrawal. Prog Neuropsychopharmacol Biol Psychiatry (1992) 16(1):87-93. doi:10.1016/ 0278-5846(92)90011-3

35. Neumann ID, Landgraf R. Balance of brain oxytocin and vasopressin: implications for anxiety, depression, and social behaviors. Trends Neurosci (2012) 35(11):649-59. doi:10.1016/j.tins.2012.08. 004

36. Reber SO, Neumann ID. Defensive behavioral strategies and enhanced state anxiety during chronic subordinate colony housing are accompanied by reduced hypothalamic vasopressin, but not oxytocin, expression. Ann N Y Acad Sci (2008) 1148:184-95. doi:10.1196/annals.1410.003

37. Ludwig M, Leng G. Dendritic peptide release and peptide-dependent behaviours. Nat Rev Neurosci (2006) 7(2):126-36. doi:10.1038/nrn1845

38. Litvin Y, Murakami G, Pfaff DW. Effects of chronic social defeat on behavioral and neural correlates of sociality: vasopressin, oxytocin and 
the vasopressinergic V1b receptor. Physiol Behav (2011) 103(3-4):393-403. doi:10.1016/j.physbeh. 2011.03.007

Received: 04 October 2013; accepted: 30 October 2013; published online: 15 November 2013.

Citation: Lee MR, Bollinger JW and Leggio $L$

(2013) Increased ethanol consumption following chronic psychosocial stress: do oxytocin and baclofen hold any therapeutic promise? Front. Psychiatry 4:148. doi: 10.3389/fpsyt.2013.00148

This article was submitted to Addictive Disorders and Behavioral Dyscontrol, a section of the journal Frontiers in Psychiatry.

Copyright (c) 2013 Lee, Bollinger and Leggio. This is an open-access article distributed under the terms of the Creative Commons Attribution License (CC BY). The use, distribution or reproduction in other forums is permitted, provided the original author(s) or licensor are credited and that the original publication in this journal is cited, in accordance with accepted academic practice. No use, distribution or reproduction is permitted which does not comply with these terms. 